\title{
Characterization of Rice Blast Resistance Genes in the Pik Cluster and Fine Mapping of the Pik-p Locus
}

\author{
Ling Wang, Xiaoke Xu, Fei Lin, and Qinghua Pan
}

Laboratory of Plant Resistance and Genetics, College of Natural Resources and Environmental Sciences, South China Agricultural University, Guangzhou, 510642, China.

Accepted for publication 15 March 2009.

\begin{abstract}
Wang, L., Xu, X., Lin, F., and Pan, Q. 2009. Characterization of rice blast resistance genes in the Pik cluster and fine mapping of the Pik-p locus. Phytopathology 99:900-905.

Pik-p is carried by cv. K60, which is one of the Japanese differentials widely used in both Japan and China since the 1980s. Its utility and specificity was evaluated with a total of 612 isolates of Magnaporthe oryzae collected from various regions in China in combination with 16 main resistance genes being used in the breeding programs. Pik-p is an independently and dominantly acting gene in the Pik cluster, which conditions differential reactions against many isolates and contains higher resistance in Guangdong, Jiangsu, and Sichuan provinces, China, indicating that this gene could be still used in these regions. A high-resolution

markers. A set of 47 recombinants out of $681 \mathrm{~F}_{2}$ plants derived from the crosses cv. K60 (resistant) $\times$ cv. AS20-1 (susceptible) and × cv. Kasalath (susceptible) was identified in the genetic interval defined by the markers RM5926 and K37 which flank the Pik gene cluster. This set was then genotyped with seven markers known to reside within the interval. The closest markers to Pik- $p$ were K28 ( $\approx 0.60$ centimorgans [cM]) and K39 $(\approx 0.07 \mathrm{cM})$. A further four markers in the K28-K39 interval were developed from an in silico analysis based on the cv. Nipponbare genome sequence, and these all co-segregated with Pik-p. This 0.67-cM region is equivalent to a physical separation in cv. Nipponbare of $\approx 126 \mathrm{~kb}$, plus an as-yet-unfilled genomic gap of unknown length. Four nucleotide-binding site leucine-rich repeat-type resistance genes are present in this interval, and these represent good candidates for Pik-p.
\end{abstract} genetic map of $P i k-p$ was constructed using genomic position-ready
Rice blast, caused by the fungus Magnaporthe oryzae, is one of the most devastating diseases of rice worldwide (10). The deployment of genetic resistance and, in particular, the breeding of cultivars protected by a spectrum of resistance $(R)$ genes, remains the most economical, effective, and environmentally sound disease control strategy. Currently, $>80$ major blast $R$ genes have been documented, approximately half of which have been genetically mapped $(4,37)$, with 9 having been isolated using a mapbased cloning approach $(2,5,9,14,19,20,28,33,35,40)$. Many plant $R$ genes are known to be organized into gene clusters $(3,25)$. On rice chromosome 11 , some $201 R$-like genes, representing $4.5 \%$ of the total number of predicted genes on this chromosome, have been identified from the cv. Nipponbare genome sequence (32). Of these, approximately one-third belongs to the nucleotidebinding site leucine-rich repeat (NBS-LRR) type. The distal region of the long arm of chromosome 11 houses a cluster of at least eight characterized rice blast $R$ genes $(1,6,7,13,18,29,31$, $36,39)$, along with a number of bacterial blight $R$ genes $(30,33,37)$.

The rice blast pathosystem largely follows the classical genefor-gene concept (16). Host recognition of the presence of the pathogen, conditioned by the interaction between a specific $R$ gene and its matching pathogen avirulence $(A v r)$ gene, leads to the activation of the defense response which, in turn, prevents colonization of the host by the pathogen. Recent findings support a more elaborate model in which the $R$ proteins detect the modification of other host proteins by pathogen effectors, rather than recognizing the effectors themselves (11). Although several $R$ genes and $A v r$ genes have been isolated to date, the molecular

Corresponding author: Q. Pan. E-mail address: panqh@scau.edu.cn

doi:10.1094/PHYTO-99-8-0900

(C) 2009 The American Phytopathological Society mechanisms underlying the $R-A v r$ interaction have been elucidated largely using the Pita-AvrPita system (16). A more general understanding of these molecular events clearly requires a diversification of the pathosystem gene pairs which can be studied at this level.

Pik- $p$ is carried by cv. K60, which is a Japanese differential cultivar widely used in both Japan and China since the 1980s (34). The race specificity of K60 is monogenic and the corresponding pathogen Avr gene, AvrPik- $p$, which may be identical to $A v r P i 7$, and is being isolated in our laboratory (12). The objective of this study was to evaluate the utility and specificity of the Pik-p gene in China, and to develop co-segregating markers linked to the Pik-p locus with a view to its marker-aided selection in the Chinese resistance breeding programs. Achieving this would provide a starting point for marker-aided gene isolation and could be a good alternative to the Pita-AvrPita pathosystem for the molecular dissection of the mechanisms underlying the host resistance response.

\section{MATERIALS AND METHODS}

Resistance characterization. To compare the specific reaction patterns and resistance frequencies among four $R$ genes at the Pik locus (17), Kusabue (Pik), K60 (Pik-p), Shin 2 (Pik-s), and Tusyuake $(P i k-m)$ were selected for resistance evaluation, with a total of 612 isolates collected from Guangdong (GD, 60 isolates), Fujian (FJ, 40 isolates), and Hunan (HN, 40 isolates) in the southern region; Guizhou (GZ, 60 isolates), Yunnan (YN, 43 isolates), and Sichuan (SC, 66 isolates) in the southwestern region; Jiangsu (JS, 72 isolates) in the eastern region; and Liaoning (LN, 108 isolates), Jilin (JL, 60 isolates), and Heilongjiang (HLJ, 63 isolates) in the northeastern region in China (Table $1)$. The resistance of each allele was evaluated as higher $(<90 \%)$, intermediate (89 to $80 \%$ ), and lower $(>80 \%)$ according to the 
resistance frequencies in the respective populations. For determining how to effectively use the resistance of the Pik- $p$ in the rice resistance breeding programs in China, the further resistance comparison was focused on 13 cultivars (lines), including the parents of those carrying the major $R$ genes being employed in the programs (Table 2).

Mapping population construction. For solely tagging Pik-p, a progeny isolate, M028, which carries AvrPik-p that was selected from a monogenic segregation population for AvrPik-p (12), was used for constructing mapping populations for the $R$ gene, Pik-p. The two test populations were $340 \mathrm{~F}_{2}$ plants derived from the cross cv. K60 (resistant) $\times$ cv. AS20-1 (population A), and $341 \mathrm{~F}_{2}$ progeny from the cross $\mathrm{cv}$. K60 $\times \mathrm{cv}$. Kasalath (population B) (Table 3). Blast inoculation and disease evaluation were performed according to Pan et al. (26). Briefly, seedlings were grown in a greenhouse at 20 to $35^{\circ} \mathrm{C}$ for $\approx 3$ weeks before inoculation. At the four- to five-leaf stage, seedlings were transferred into an inoculation chamber and inoculated by spraying with spore suspension at $1 \times 10^{5} \mathrm{conidia} / \mathrm{ml}$. After inoculation, the seedlings were kept in the chamber at $25^{\circ} \mathrm{C}$ with saturated humidity for $20 \mathrm{~h}$, and then transferred to a moist vinyl tunnel at 20 to $35^{\circ} \mathrm{C}$. Disease reactions were scored for $\approx 7$ days after inoculation by use of a 0 -to- 5 disease scale, where the seedlings of scores 0 to 2 were referred to as resistant and those of scores 3 to 5 were referred to as susceptible.

Molecular marker development. Because Pik-p was thought to be either an allele of or at least tightly linked to Pik-m, which has been successfully mapped by Li et al. (18), it was possible to exploit all the molecular markers used for the mapping of Pik-m. A number of additional Pik-p-specific markers were developed by a strategy based on an in silico analysis, as has described elsewhere $(8,18,21)$. An overview of the polymerase chain reaction (PCR)-based markers used in the current study is given in Table 4.

Genetic map construction. A bulk segregant analysis (BSA) was carried out to identify molecular makers linked to Pik-p $(8,21)$. Similar linkage relationships emerging from the two $F_{2}$ populations enabled their combination into a single mapping population of 681 plants $(8,18)$. A genetic linkage map was constructed on the basis of recombination frequencies, as described previously $(22,26)$.

In silico physical map construction. Based on the genetic map of Pik- $p$, an in silico localized physical map was constructed, using the reference sequence of cv. Nipponbare $(8,18,21,22)$. First, primer sequences of the linked molecular markers were matched to the bacterial artificial chromosome (BAC) of cv. Nipponbare released by the International Rice Genome Sequencing Project (IRGSP) (http://rgp.dna.affrc.go.jp/IRGSP) through BLASTN analysis. Second, sequences of the matched clones were aligned using another bio-software tool, Pairwise BLAST. The physical map covering the $R$ gene locus was consequently constructed based on these aligned sequences of $\mathrm{cv}$. Nipponbare.

\section{RESULTS}

Characterization of the Pik-p gene. Numerous differential reactions were identified among the four $R$ genes in the various populations tested, indicating that the Pik-p could be distinguished from the other three alleles at the Pik locus with these reactions (Table 1). In the FJ, YN, JS, and HLJ populations, the resistance frequencies in decreasing order among the four $R$ genes were Pik-m $>$ Pik $>$ Pik- $p>$ Pik-s, which is in agreement with the supposition described by Kiyosawa (17). In the other populations, the resistance frequency is not ordered as Pik-m $>$ Pik $>$ Pik- $p>$ Pik-s. Because the Pik-p gene contains higher resistance in GD (96.7\%), JS (90.9\%), and SC (90.9\%), it means that the Pik-p gene expresses province-specific resistance in the various ricegrowing regions in China, and that could be effectively used in
GD, JS, and SC provinces. In addition, numerous complementary reactions were identified in the various populations compared with other main $R$ genes being used in the Chinese resistance breeding programs (Table 2), indicating that the Pik-p gene could be incorporated in elite cultivars with other $R$ genes such as Pita, Pita-2, Piz, Piz-t , Pib, and Pi9, which have been finely mapped and even isolated.

Recombinant screening and mapping population construction. Distinct reactions were observed among three parental cultivars and their $\mathrm{F}_{2}$ progenies when challenged with the progeny isolate M028 (only parental cultivar reactions shown in Table 2). The segregation of blast resistance in both $F_{2}$ populations fit a monogenic ratio (Table 3), suggesting that Pik-p behaves as a single dominant gene controlling blast resistance. To verify that the resistance was determined by a gene on chromosome 11, the five simple-sequence repeat (SSR) markers (RM254, RM456C, RM224, RM7443, and RM5926) which map to the distal region of the long arm (23) were applied to test for polymorphism

TABLE 1. Comparison of specific reaction patterns and resistance frequencies among resistance genes Pik-p, Pik-s, Pik, and Pik-m located at the Pik cluster in the 10 Magnaporthe oryzae populations collected in China

\begin{tabular}{|c|c|c|c|c|}
\hline \multirow[b]{2}{*}{ Population $^{\mathrm{a}}$} & \multicolumn{4}{|c|}{ Cultivar (gene) $^{\mathrm{b}}$} \\
\hline & $\begin{array}{l}\text { Shin 2 } \\
(P i k-s)\end{array}$ & $\begin{array}{c}\text { K60 } \\
(P i k-p)\end{array}$ & $\begin{array}{c}\text { Kusabue } \\
(P i k)\end{array}$ & $\begin{array}{c}\text { Tsuyuake } \\
(\text { Pik-m) }\end{array}$ \\
\hline \multicolumn{5}{|l|}{ GD isolates } \\
\hline CHL1968 & $\mathrm{S}$ & $\mathrm{R}$ & $\mathrm{R}$ & $\mathrm{S}$ \\
\hline CHL2007 & $\mathrm{S}$ & $\mathrm{R}$ & $\mathrm{R}$ & $\mathrm{S}$ \\
\hline Frequency (\%) & 21.7 & 96.7 & 100 & 93.3 \\
\hline \multicolumn{5}{|l|}{ FJ isolates } \\
\hline CHL487 & $\mathrm{R}$ & $\mathrm{S}$ & $\mathrm{R}$ & $\mathrm{R}$ \\
\hline CHL518 & $\mathrm{S}$ & $\mathrm{S}$ & $\mathrm{R}$ & $\mathrm{R}$ \\
\hline Frequency $(\%)$ & 5 & 45 & 89.8 & 95 \\
\hline \multicolumn{5}{|l|}{$\mathrm{HN}$ isolates } \\
\hline CHL412 & $\mathrm{S}$ & $\mathrm{S}$ & $\mathrm{R}$ & $\mathrm{R}$ \\
\hline CHL479 & $\mathrm{S}$ & $\mathrm{S}$ & $\mathrm{R}$ & $\mathrm{R}$ \\
\hline Frequency $(\%)$ & 10 & 80 & 97.5 & 97.5 \\
\hline \multicolumn{5}{|l|}{ YN isolates } \\
\hline CHL207 & $\mathrm{S}$ & $\mathrm{S}$ & $\mathrm{S}$ & $\mathrm{R}$ \\
\hline CHL250 & $\mathrm{R}$ & $\mathrm{S}$ & $\mathrm{R}$ & $\mathrm{R}$ \\
\hline Frequency (\%) & 14 & 53.4 & 67.4 & 86 \\
\hline \multicolumn{5}{|l|}{$\mathrm{GZ}$ isolates } \\
\hline CHL583 & $\mathrm{S}$ & $\mathrm{S}$ & $\mathrm{R}$ & $\mathrm{R}$ \\
\hline CHL590 & $\mathrm{S}$ & $\mathrm{R}$ & $\mathrm{R}$ & $\mathrm{S}$ \\
\hline Frequency (\%) & 13.3 & 73.3 & 86.7 & 81.7 \\
\hline \multicolumn{5}{|l|}{$\mathrm{SC}$ isolates } \\
\hline CHL871 & $\mathrm{S}$ & $\mathrm{R}$ & $\mathrm{R}$ & $\mathrm{S}$ \\
\hline CHL901 & $\mathrm{S}$ & $\mathrm{R}$ & $\mathrm{S}$ & $\mathrm{S}$ \\
\hline Frequency $(\%)$ & 54.5 & 90.9 & 97 & 95.5 \\
\hline \multicolumn{5}{|l|}{ JS isolates } \\
\hline CHL335 & $\mathrm{S}$ & $\mathrm{S}$ & $\mathrm{R}$ & $\mathrm{R}$ \\
\hline CHL359 & $\mathrm{R}$ & $\mathrm{S}$ & $\mathrm{R}$ & $\mathrm{R}$ \\
\hline Frequency (\%) & 2.8 & 90.9 & 94.4 & 95.5 \\
\hline \multicolumn{5}{|l|}{$\mathrm{LN}$ isolates } \\
\hline EL0401 & $\mathrm{S}$ & $\mathrm{R}$ & $\mathrm{R}$ & $\mathrm{S}$ \\
\hline EL0466 & $\mathrm{S}$ & $\mathrm{S}$ & $\mathrm{S}$ & $\mathrm{S}$ \\
\hline Frequency (\%) & 0.9 & 38.9 & 52.8 & 38.9 \\
\hline \multicolumn{5}{|l|}{$\mathrm{JL}$ isolates } \\
\hline CHL703 & $\mathrm{S}$ & $\mathrm{S}$ & $\mathrm{R}$ & $\mathrm{R}$ \\
\hline CHL762 & $\mathrm{S}$ & $\mathrm{R}$ & $\mathrm{S}$ & $\mathrm{S}$ \\
\hline Frequency (\%) & 3.3 & 23.3 & 21.7 & 26.7 \\
\hline \multicolumn{5}{|l|}{ HLJ isolates } \\
\hline CHL775 & $\mathrm{S}$ & $\mathrm{R}$ & $\mathrm{S}$ & $\mathrm{S}$ \\
\hline CHL777 & $\mathrm{S}$ & $\mathrm{S}$ & $\mathrm{S}$ & $\mathrm{S}$ \\
\hline Frequency $(\%)$ & 15.9 & 17.5 & 20.6 & 25.4 \\
\hline
\end{tabular}

a Populations: GD (Guangdong, 60 isolates), FJ (Fujian, 40 isolates), and HN (Hunan, 40 isolates) in the southern region; YN (Yunnan, 43 isolates), GZ (Guizhou, 60 isolates), and SC (Sichuan, 66 isolates) in the southwestern region; JS (Jiangsu, 72 isolates) in the eastern region; and LN (Liaoning, 108 isolates), JL (Jilin, 60 isolates), and HLJ (Heilongjiang, 63 isolates) in the northeastern region in China. Frequency $=$ resistance frequency.

b Specific reaction patterns selected in the respective populations: $\mathrm{R}=$ resistant and $\mathrm{S}=$ susceptible. 
between the resistant and susceptible parental lines and BSA bulks. Only RM5926, the most telomeric of these, identified such a polymorphism (data not shown), and delivered 28 recombinants with resistance in population $\mathrm{A}$ (equivalent to $\approx 4.1$ centimorgans $[\mathrm{cM}])$, but only 14 in population $\mathrm{B}(\approx 2.1 \mathrm{cM})$ (Table 3$)$. The second most centromeric marker, K37 (18), was informative in both crosses and, therefore, was used to identify recombinants on the centromeric side of Pik- $p$. Applying this assay to the two segregating populations resulted in the detection of three and two recombinants, respectively (Table 3 ), equivalent to map distances of $\approx 0.4$ and $\approx 0.3 \mathrm{cM}$, respectively. Thus, in the pooled population of 681 individuals, Pik-p was flanked on the telomeric side by RM5926 and on the centromeric side by K37, with its location defined by 47 recombinants (Table 3; Fig. 1).

Construction of a high-resolution genetic map. Initially, the seven markers RM144, K25, K15-2, K22, K28, K34, and K39, all located in the interval flanked by markers RM5926 and K37, were used to genotype the 47 recombinants between RM5926 and K37 (Table 4; Fig. 1). Three of these (RM144, K25, and K15-2) were informative in population A but not in population B (Fig. 1C). The analysis identified 17,9 , and 8 recombinants, respectively, with respect to RM5926 in population A. K22 and K28, mapping on the telomeric side of Pik-p, produced 12 and 8 recombinants, respectively, with respect to RM5926, equivalent to a map distance between Pik-p and K28 of $0.6 \mathrm{cM}$ (Fig. 1). On the centromeric side, there were two and one recombinants, respectively, between K34, K39, and Pik-p, giving an estimate of $0.07 \mathrm{cM}$ for the genetic interval between K39 and Pik-p (Fig. 1). For a second round of mapping, markers K33, K40, K41, and K42 were developed. The focus for marker development was the region defined by K28 and K39. Complete linkage was obtained between Pik-p and all four of these markers (Fig. 1). Thus, the location of Pik-p was narrowed to a $0.67-\mathrm{cM}$ region defined by K28 and K39.

Construction of an in silico physical map. Because the same delimiting markers (RM5926 and K37) were also used for the analysis of Pik-m (18), the Pik-m contig and physical maps were directly utilizable for the analysis of Pik-p. The Pik-p anchor markers were aligned to the cv. Nipponbare sequence and, based on these positions, a physical map covering Pik- $p$ was assembled (Fig. 1B). The K39 to K28 segment covers $\approx 126 \mathrm{~kb}$, plus a genomic gap of unknown length separating BAC clones OSJNBa0047M04 and OSJNBa0036K13. Critically, Pik-p is distinct from $P i k-m$, because there are eight recombinants between K28 and Pik-p but none between the same marker and Pik-m (18) (Fig. 1).

\section{DISCUSSION}

We have constructed a high-resolution genetic map in the region of Pik-p, which will be of particular use for the selection of closely linked markers for blast $R$ gene stacking (15). Pik- $p$ is associated with a higher level of resistance against pathogen populations originating from GD, JS, and SC provinces and with an intermediate resistance against those from $\mathrm{HN}$ and $\mathrm{GZ}$ provinces, but with a lower level against those from YN, FJ, LN, JL, and HLJ provinces. This implies that the gene should be beneficial for blast resistance breeding programs in the former three provinces, and we are currently initiating a joint project with rice breeders in these regions to exploit the genetic linkages.

On the basis of resistance spectra against Japanese isolates, Kiyosawa (17) inferred semi-fine structures of the four alleles at the Pik locus, in which Pik, Pik-p, and Pik-s all form part of the larger or stronger allele, Pik-m (Fig. 2). That is, the resistance

TABLE 2. Differential reactions of 3 parental rice cultivars and 11 cultivars carrying the main resistance genes being used in the Chinese breeding programs to the progeny isolate M028 and 15 isolates of Magnaporthe oryzae selected from Guangdong (GD), Sichuan (SC), Jiangsu (JS), Jilin (JL), and Heilongjiang (HLJ) provinces, China ${ }^{\mathrm{a}}$

\begin{tabular}{|c|c|c|c|c|c|c|c|c|c|c|c|c|c|c|c|c|c|}
\hline \multirow[b]{2}{*}{ Cultivar $^{\mathrm{b}}$} & \multirow[b]{2}{*}{ Gene } & \multicolumn{3}{|c|}{ GD isolates } & \multicolumn{3}{|c|}{$\mathrm{SC}$ isolates } & \multicolumn{3}{|c|}{ JS isolates } & \multicolumn{3}{|c|}{ JL isolates } & \multicolumn{3}{|c|}{ HLJ isolates } & \multirow[b]{2}{*}{ M028 } \\
\hline & & CHL1880 & 0 CHL1946 & CHL2089 & CHL842 & CHL867 & CHL930 & CHL333 & CHL350 & CHL409 & CHL678 & CHL684 & CHL693 & CHL768 & CHL772 & CHL776 & \\
\hline $\begin{array}{l}\text { Set A } \\
\text { K60 }\end{array}$ & Pik-p & $\mathrm{R}$ & $\mathrm{R}$ & $\mathrm{S}$ & $\mathrm{R}$ & $\mathrm{R}$ & $\mathrm{R}$ & $\mathrm{R}$ & $\mathrm{R}$ & $\mathrm{R}$ & $\mathrm{S}$ & $\mathrm{S}$ & $\mathrm{S}$ & $\mathrm{S}$ & $\mathrm{S}$ & $\mathrm{S}$ & $\mathrm{R}$ \\
\hline AS20-1 & Pi26 & $\mathrm{S}$ & $\mathrm{S}$ & $\mathrm{S}$ & S & $\mathrm{S}$ & $\mathrm{S}$ & $\mathrm{S}$ & $\mathrm{S}$ & $\mathrm{S}$ & $\mathrm{S}$ & $\mathrm{S}$ & $\mathrm{S}$ & $\mathrm{S}$ & $\mathrm{S}$ & $\mathrm{S}$ & $S$ \\
\hline Set B & & & & & & & & & & & & & & & & & \\
\hline K1 & Pita & $\mathrm{R}$ & $\mathrm{R}$ & $\mathrm{R}$ & $\mathrm{S}$ & $\mathrm{R}$ & $\mathrm{S}$ & $\mathrm{S}$ & $\mathrm{S}$ & $\mathrm{S}$ & $\mathrm{S}$ & $\mathrm{S}$ & $\mathrm{S}$ & $\mathrm{S}$ & $\mathrm{R}$ & $\mathrm{S}$ & $\mathrm{R}$ \\
\hline Toride 1 & Piz- $t$ & $\mathrm{~S}$ & $\mathrm{R}$ & $\mathrm{S}$ & $\mathrm{S}$ & $\mathrm{S}$ & $\mathrm{S}$ & $\mathrm{R}$ & $\mathrm{R}$ & $\mathrm{R}$ & $\mathrm{R}$ & $\mathrm{R}$ & $\mathrm{R}$ & $\mathrm{R}$ & $\mathrm{R}$ & $\mathrm{R}$ & $\mathrm{R}$ \\
\hline BL1 & $P i b$ & $\mathrm{~S}$ & $\mathrm{R}$ & $\mathrm{S}$ & $\mathrm{S}$ & $\mathrm{S}$ & $\mathrm{S}$ & $\mathrm{R}$ & $\mathrm{S}$ & $\mathrm{S}$ & $\mathrm{R}$ & $\mathrm{R}$ & $\mathrm{R}$ & $\mathrm{R}$ & $\mathrm{R}$ & $\mathrm{R}$ & $\mathrm{R}$ \\
\hline C101LAC & Pil & $\mathrm{R}$ & $\mathrm{R}$ & $\mathrm{R}$ & $\mathrm{R}$ & $\mathrm{R}$ & $\mathrm{R}$ & $\mathrm{R}$ & $\mathrm{R}$ & $\mathrm{R}$ & $\mathrm{S}$ & $\mathrm{S}$ & $\mathrm{S}$ & $\mathrm{R}$ & $\mathrm{S}$ & $\mathrm{R}$ & $\mathrm{R}$ \\
\hline C101A51 & Pi2 & $\mathrm{R}$ & $\mathrm{R}$ & $\mathrm{R}$ & $\mathrm{R}$ & $\mathrm{R}$ & $\mathrm{R}$ & $\mathrm{R}$ & $\mathrm{R}$ & $\mathrm{R}$ & $\mathrm{S}$ & $\mathrm{S}$ & $\mathrm{S}$ & $\mathrm{R}$ & $\mathrm{S}$ & $\mathrm{S}$ & $\mathrm{S}$ \\
\hline C104PKT & Pi3 & S & $\mathrm{R}$ & S & $\mathrm{S}$ & $\mathrm{S}$ & S & $\mathrm{R}$ & $\mathrm{R}$ & $\mathrm{R}$ & $\mathrm{S}$ & $\mathrm{S}$ & S & S & $\mathrm{S}$ & $\mathrm{S}$ & $\mathrm{R}$ \\
\hline C101PKT & Pi4 & $\mathrm{S}$ & $\mathrm{R}$ & $\mathrm{S}$ & $\mathrm{S}$ & $\mathrm{R}$ & $\mathrm{S}$ & $\mathrm{S}$ & $\mathrm{R}$ & $\mathrm{R}$ & $\mathrm{R}$ & $\mathrm{S}$ & $\mathrm{S}$ & $\mathrm{S}$ & $\mathrm{S}$ & $\mathrm{R}$ & $\mathrm{S}$ \\
\hline IRBL20 & Pi5 & $\mathrm{R}$ & $\mathrm{S}$ & $\mathrm{R}$ & S & $\mathrm{S}$ & $\mathrm{S}$ & $\mathrm{R}$ & $\mathrm{R}$ & $\mathrm{R}$ & $\mathrm{S}$ & $\mathrm{S}$ & S & S & $\mathrm{S}$ & $\mathrm{S}$ & ND \\
\hline
\end{tabular}

${ }^{a} \mathrm{R}=$ resistant, $\mathrm{S}=$ susceptible, and $\mathrm{ND}=$ not determined.

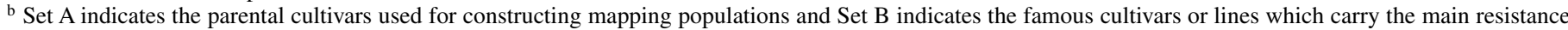
genes employed in Chinese breeding programs.

c Progeny isolate M028 was selected from a mapping population for AvrPik-p that is identical to AvrPi7 (12).

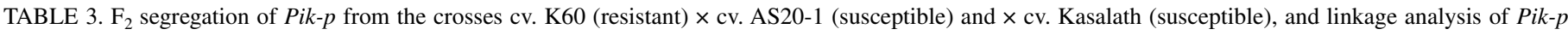
with respect to the flanking markers K37 and RM5926

\begin{tabular}{|c|c|c|c|c|c|c|c|c|c|}
\hline \multirow[b]{2}{*}{ Population code } & \multirow[b]{2}{*}{ Cross } & \multirow[b]{2}{*}{ Isolate $^{\mathrm{a}}$} & \multicolumn{3}{|c|}{ No. of $F_{2}$ plants } & \multirow[b]{2}{*}{$\chi^{2 \mathrm{~b}}$} & \multirow[b]{2}{*}{$\operatorname{Size}^{\mathrm{c}}$} & \multicolumn{2}{|c|}{ Recombinants } \\
\hline & & & Resistant & Susceptible & Total & & & K37 & RM5926 \\
\hline A & $\mathrm{K} 60 \times \mathrm{AS} 20-1$ & M028 & 1,038 & 316 & 1,354 & 1.9 & 340 & 3 & 28 \\
\hline B & K60 $\times$ Kasalath & M028 & 1,041 & 310 & 1,351 & 2.3 & 341 & 2 & 14 \\
\hline
\end{tabular}

a Test isolate carries the avirulence gene AvrPik-p.

b For 3:1 ratio.

c Population size. Viable susceptible $\mathrm{F}_{2}$ plants along with a random selection of resistant $\mathrm{F}_{2}$ plants. 
TABLE 4. Polymerase chain reaction (PCR)-based markers used for genetic mapping of Pik-p

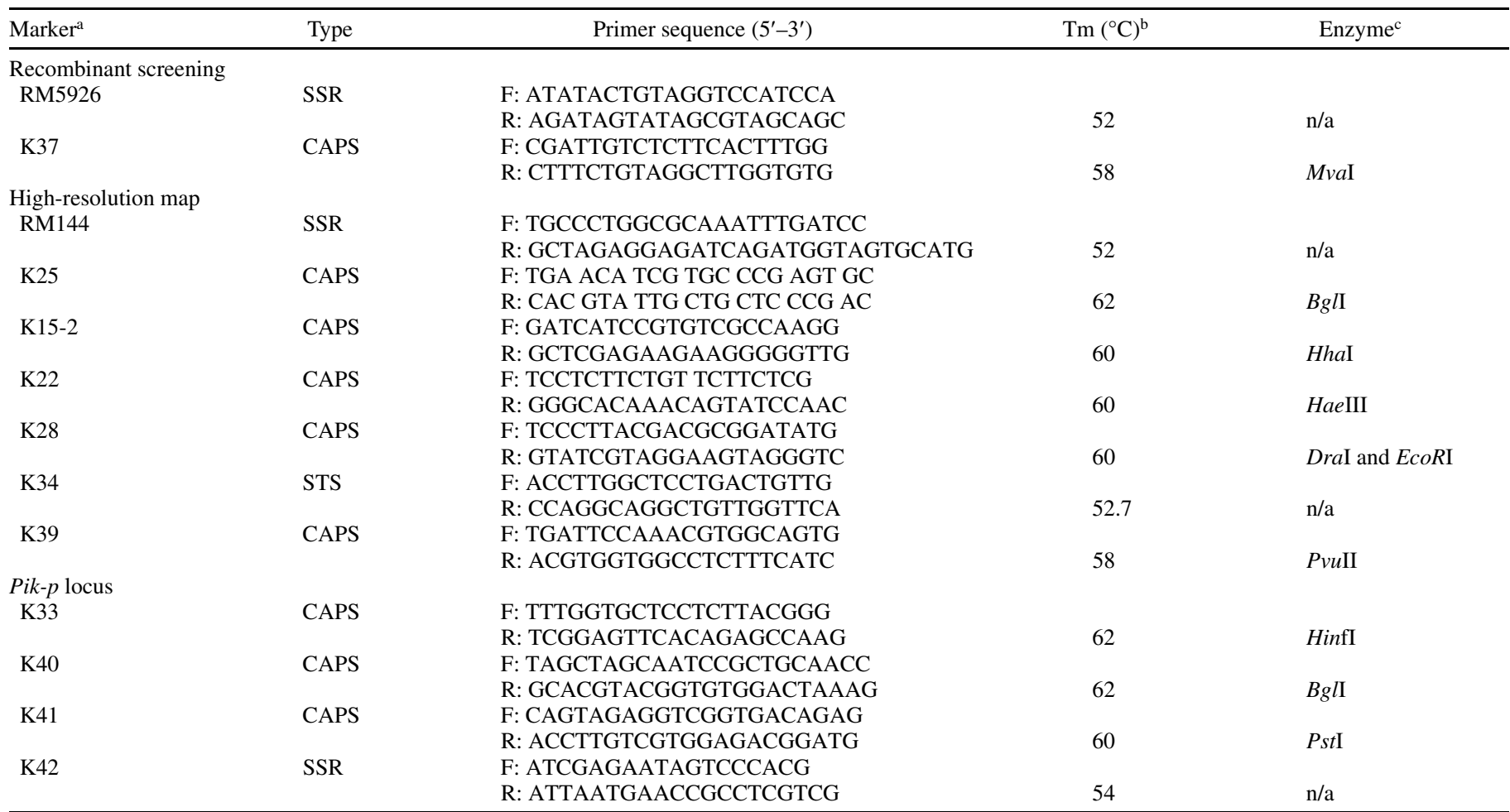

${ }^{a}$ Markers used for recombinant screening or high-resolution map, or cosegregated with Pik-p locus. Markers prefixed with RM (i.e., RM5926 and RM224) were adopted from McCouch et al. (23) and those prefixed with $\mathrm{K}$ were developed in our laboratory.

${ }^{\mathrm{b}}$ Annealing temperature.

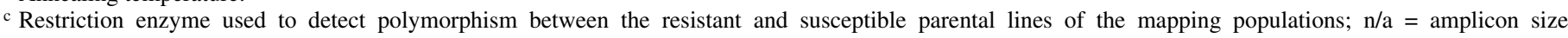
polymorphism, not requiring post-PCR restriction digestion.

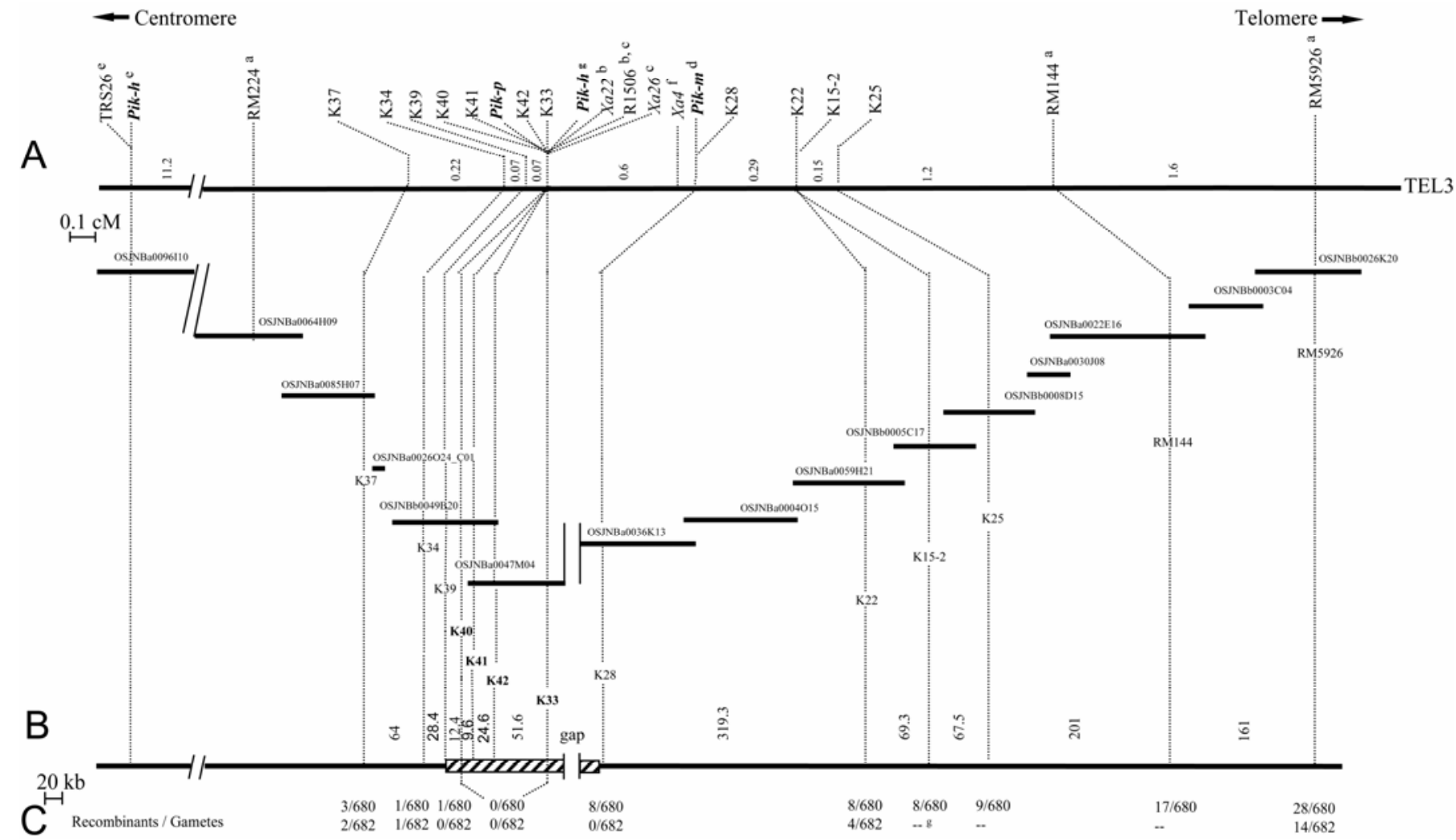

Fig. 1. Rice chromosome 11 genetic and physical maps in the region of Pik-p. A, Integrated genetic map of the six resistance genes mapping to the end of rice chromosome 11. Map positions extracted from (a) McCouch et al. (23), (b) Wang et al. (33), (c) Yang et al. (38), (d) Li et al. (18), (e) Sharma et al. (29), (f) Sun et al. (30), and (g) Xu et al. (36). B, Physical map of Pik-p, constructed from the cv. Nipponbare genomic sequence. The long black horizontal line represents rice chromosome 11, the shaded bars represent the Pik-p region, and the short horizontal bars represent overlapping cv. Nipponbare bacterial artificial chromosome (BAC) clones. The positions of the markers on the BAC clones are indicated by vertical dotted lines. C, Recombinants between marker loci and Pik-p. The upper figure corresponds to mapping population $\mathrm{A}$, and the lower to mapping population $\mathrm{B}$; $\mathrm{g}$ ) indicates noninformative markers in population $\mathrm{B}$. 
spectra of Pik-m might cover those of Pik, Pik-p, and Pik-s. As to Chinese isolates, however, we have identified many isolates which are virulent to Pik-m but avirulent to Pik and Pik-p in the various populations (Table 1). Resistance spectra were ordered as Pik- $m>$ Pik $>$ Pik- $p>$ Pik-s in FJ, YN, JS, and HLJ populations but this was not the case for the remaining six populations tested, where some resistance frequencies of $P i k$ and even Pik-p were higher than those of $P i k-m$ (Table 1). The results from the present study indicated that the alleles Pik-m, Pik, Pik-p, and Pik-s at the $P i k$ locus are, indeed, independent $R$ genes that condition respective reactions against various isolates. This further indicates that these $R$ genes in a cluster could also be stacked in elite cultivars through marker-aided selection approach.

The integrated genetic and physical map provides some further insight into the organization and evolution of the chromosome 11 $R$ gene cluster. Currently, some six functional $R$ genes-specifically, Pik-h (36), Pik-m (18), and Pik-p, along with Xa4 (30), $\mathrm{Xa22}(23)$ and $\mathrm{Xa26}(38)$ - together with at least $30 \mathrm{R}$-like genes of unknown function, have been located within the 110- to 119-cM region of chromosome 11 (32). Similarly, conventional allelism tests concluded that Pik, Pik-s, Pik-m, Pik-p, Pik-h, and $P i k-g$ are all alleles at a single locus (27); the present genetic data show conclusively that marker K28 lies between Pik-p and Pik-m and, thus, that these two $R$ genes must be, by definition, nonallelic. Furthermore, the most promising candidate genes of both $R$ genes are different: the former is predicted as NBS-LRR and the latter is protein kinase (18). $R$ genes within a single cluster can follow strikingly distinct evolutionary trajectories, as has been suggested by McDowell and Simon (24).

As has been commonly documented $(18,30,33,38)$, the ratio between the physical and the genetic distance across an $R$ gene cluster can be very uneven. Variation in this ratio appears to depend not only on the genomic context but also on the genetic background (Table 3; Fig. 1C). In the K37-K40 interval, the rate of recombination in the two populations was highly similar, but this was not the case for the RM5926-K33 interval, where fewer recombinants emerged in population $\mathrm{B}$.

A physical map is a prerequisite for attempting map-based cloning $(19,21)$. Pik- $p$ has now been delimited to a 126-kb interval plus a genomic gap bounded by markers K39 and K28 and including four co-segregating markers (Fig. 1). In this region, a

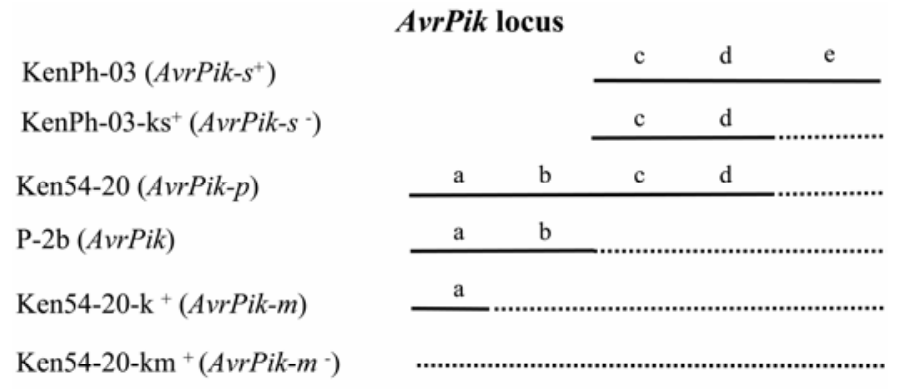

\section{Pik locus}

\begin{tabular}{|c|c|c|c|c|c|}
\hline Pik-m & $\mathrm{A}$ & B & $\mathrm{C}$ & D & $\mathrm{E}$ \\
\hline Pik & & B & $\mathrm{C}$ & D & $\mathrm{E}$ \\
\hline Pik-p & & & $\mathrm{C}$ & D & \\
\hline Pik-s & & & & D & E \\
\hline
\end{tabular}

Fig. 2. Presumed semifine structures of resistance $(R)$ genes at $P i k$ locus and their corresponding avirulence (Avr) genes at AvrPik locus (adopted from Kiyosawa [17]). The black horizontal line represents active sites and the dotted line represents inactive sites. Uppercase letters represent an active site in $R$ gene and lowercase letters represent an active site in its corresponding Avr gene. bioinformatic analysis has identified a maximum of four NBSLRR-type genes (data not shown). A new BAC contig (consisting of clones AC129339, AC135189, and AC131246) has recently been mapped into the genomic gap mentioned above; however, no $R$ gene homologue could be identified in this $>300-\mathrm{kb}$ contig. We are currently targeting the four candidate NBS-LRR genes to determine which, if any, of these represent Pik-p.

\section{ACKNOWLEDGMENTS}

L. Wang and $\mathrm{X}$. Xu contributed equally to this work. We thank $\mathrm{Z}$. Wang (Fujian Agricultural University), Z. Zhao (Agricultural Academy Sciences of Huan Province), D. Lu (Agricultural Academy Sciences of Sichuan Province), Y. Zhu (Yunnan Agricultural University), J. Yuan (Agricultural Academy Sciences of Guizhou Province), X. Zheng (Nanjing Agricultural University), Z. Liu (Shenyang Agricultural University), X. Guo (Agricultural Academy Sciences of Jilin Province), and G. Zhang (Agricultural Academy Sciences of Heilongjing Province) for providing isolates used in the present research. Support for this research was provided by the National 973 project (2006CB/1002006), the National Commonweal Specialized Research Project (200803008), and the National 863 projects (2006AA100101 and 2006AA10A103). This manuscript was selected as a feature article through the APS/CSPP Cooperative Agreement.

\section{LITERATURE CITED}

1. Ahn, S. N., Kim, Y. K., Hong, H. C., Han, S. S., Kwon, S. J., Choi, H. C., Moon, H. P., and McCouch, S. R. 2000. Molecular mapping of a new gene for resistance to rice blast (Pyricularia grisea Sacc.). Euphytica 116:17-22.

2. Ashikawa, I., Hayashi, N., Yamane, H., Kanamori, H., Wu, J., Matsumoto, T., Ono, K., and Yano, M. 2008. Two adjacent NBS-LRR class genes are required to confer Pikm-specific rice blast resistance. Genetics 180:22672276.

3. Bai, J. F., Pennill, L. A., Ning, J., Lee, S. W., Ramalingam, J., Webb, C. A., Zhao, B., Sun, Q., Nelson, J. C., Leach, J. E., and Hulbert, S. H. 2002. Diversity in nucleotide binding site-leucine-rich repeat genes in cereals. Genome Res. 12:1871-1884.

4. Ballini, E., Morel, J. B., Droc, G., Price, A., Courtois, B., Notteghem, J. L., and Tharreau, D. 2008. A genome-wide meta-analysis of rice blast resistance genes and quantitative trait loci provides new insights into partial and complete resistance. Mol. Plant-Microbe Interact. 21:859-868.

5. Bryan, G. T., Wu, K. S., Farrall, L., Jia, Y., Hershey, H. P., McAdams, S. A., Faulk, K. N., Donaldson, G. K., Tarchini, R., and Valent, B. 2000. A single amino acid difference distinguishes resistant and susceptible alleles of the rice blast resistance gene Pi-ta. Plant Cell 12:2033-2045.

6. Cambell, M. A., Chen, D., and Ronald, P. C. 2004. Development of codominant amplified polymorphic sequence markers in rice that flank the Magnaporthe grisea gene $P i 7(\mathrm{t})$ in recombinant inbred line 29. Phytopathology 94:302-307.

7. Chen, D. H., dela Vina, M., Inukai, T., Mackill, D. J., Ronald, P. C., and Nelson, R. J. 1999. Molecular mapping of the blast resistance gene, Pi44(t), in a line derived from a durably resistant rice cultivar. Theor. Appl. Genet. 98:1046-1053.

8. Chen, S., Wang, L., Que, Z., Pan, R., and Pan, Q. H. 2005. Genetic and physical mapping of $P i 37(\mathrm{t})$, a new gene conferring resistance to rice blast in the famous cultivar St. No. 1. Theor. Appl. Genet. 111:1563-1570.

9. Chen, X. W., Shang, J. J., Chen, D. X., Lei, C. L., Zou, Y., Zhai, W. X., Liu, G. Z., Xu, J. C., Ling, Z. Z., Cao, G., Ma, B. T., Wang, Y. P., Zhao, X. F., Li, S. G., and Zhu, L. H. 2006. A B-lectin receptor kinase gene conferring rice blast resistance. Plant J. 46:794-804.

10. Couch, B. C., and Kohn, L. M. 2002. A multilocus gene genealogy concordant with host preference indicates segregation of a new species, Magnaporthe oryzae, from M. grisea. Mycologia 94:683-693.

11. Dangl, J. L., and Jones, J. D. 2001. Plant pathogens and integrated defense responses to infection. Nature 411:826-833.

12. Feng, S., Ma, J., Lin, F., Wang, L., and Pan, Q. H. 2007. Construction of an electronic physical map of Magnaporthe oryzae using genomic position-ready SSR markers. Chin. Sci. Bull. 52:3346-3354.

13. Gowda, M., Barman-Roy, S., and Chattoo, B. B. 2006. Molecular mapping of a novel blast resistance gene Pi38 in rice using SSLP and AFLP markers. Plant Breed. 125:596-599.

14. Hayashi, K., and Yoshida, H. 2009. Refunctionalization of the ancient rice blast disease resistance gene Pit by the recruitment of a retrotransposon as a promoter. Plant J. 57:413-425.

15. Hittalmani, S., Parco, A., Mew, T. V., Zeigler, R. S., and Huang, N. 2000. Fine mapping and DNA marker-assisted pyramiding of the three major genes for blast resistance in rice. Theor. Appl. Genet. 100:1121-1128. 
16. Jia, Y. L., McAdams, S. A., Bryan, G. T., Hershey, H. P., and Valent, B. 2000. Direct interaction of resistance gene and avirulence gene products confers rice blast resistance. EMBO J. 19:4004-4014.

17. Kiyosawa, S. 1987. With genetic view on the mechanisms of resistance and virulence. Jpn J. Iden. 41:89-92. (In Japanese)

18. Li, L., Wang, L., Jing, J., Li, Z., Lin, F., Huang, L., and Pan, Q. H. 2007. The $P i k^{\mathrm{m}}$ gene, conferring stable resistance to isolates of Magnaporthe oryzae, was finely mapped in a crossover-cold region on rice chromosome 11. Mol. Breed. 20:179-188.

19. Lin, F., Chen, S., Que, Z., Wang, L., Liu, X., and Pan, Q. H. 2007. The blast resistance gene Pi37 encodes a nucleotide binding site-leucine-rich repeat protein and is a member of a resistance gene cluster on rice chromosome 1. Genetics 177:1871-1880.

20. Liu, X., Lin, F., Wang, L., and Pan, Q. H. 2007a. The in silico map-based cloning of Pi36, a rice coiled-coil-nucleotide-binding site-leucine-rice repeat gene that confers race-specific resistance to the blast fungus. Genetics 176:2541-2549.

21. Liu, X., Wang, L., Chen, S., Lin, F., and Pan, Q. H. 2005. Genetic and physical mapping of $P i 36(\mathrm{t})$, a novel rice blast resistance gene located on rice chromosome 8. Mol. Gen. Genomics 274:394-401.

22. Liu, X., Yang, Q., Lin, F., Hua, L., Wang, C., Wang, L., and Pan, Q. H. 2007b. Identification and fine mapping of Pi39(t), a major gene conferring the broad-spectrum resistance to Magnaporthe oryzae. Mol. Gen. Genomics 278:403-410.

23. McCouch, S. R., Teytelman, L., Xu, Y. B., Lobos, K. B., Clare, K., Walton, M., Fu, B. Y., Maghirang, R., Li, Z. K., Xing, Y. Z., Zhang, Q. F., Kono, I., Yano, M., Fjellstrom, R., Declerck, G., Schneider, D., Cartinhour, S., Ware, D., and Stein, L. 2002. Development and mapping of 2240 new SSR markers for rice (Oryza sativa L.). DNA Res. 9:199207.

24. McDowell, J. M., and Simon, S. A. 2006. Recent insights into $R$ gene evolution. Mol. Plant Pathol. 7:437-448.

25. Monosi, B., Wisser, R. J., Pennill, L., and Hulbert, S. H. 2004. Fullgenome analysis of resistance gene homologues in rice. Theor. Appl. Genet. 109:1434-1447.

26. Pan, Q. H., Hu, Z., Tanisaka, T., and Wang, L. 2003. Fine mapping of the blast resistance gene Pi15, linked to Pii, on rice chromosome 9. Acta Bot. Sin. 45:871-877.

27. Pan, Q. H., Wang, L., Tanisaka, T., and Ikehashi, H. 1998. Allelism of rice blast resistance genes in two Chinese rice cultivars, and identification of two new resistance genes. Plant Pathol. 47:165-170.

28. Qu, S., Liu, G., Zhou, B., Bellizzi, M., Zeng, L., Dai, L. Y., Han, B., and Wang, G. L. 2006. The broad-spectrum blast resistance gene Pi9 encodes an NBS-LRR protein and is a member of a multigene family in rice. Genetics 172:1901-1914.

29. Sharma, T. R., Madhav, M. S., Singh, B. K., Shanker, P., Jana, T. K., Dalal, V., Pandit. A., Singh, A., Gaikwad, K., Upreti, H. C., and Singh, N.
K. 2005. High-resolution mapping, cloning and molecular characterization of the $P i-k^{h}$ gene of rice, which confers resistance to Magnaporthe grisea. Mol. Gen. Genomics 274:569-578.

30. Sun, X., Yang, Z., Wang, S., and Zhang, Q. 2003. Identification of a 47-kb DNA fragment containing $\mathrm{Xa} 4$, a locus for bacterial blight resistance in rice. Theor. Appl. Genet. 106:683-687.

31. Tabien, R. E., Li, Z., Paterson, A. H., Marchetti, M. A., Stansel, J. W., and Pinson, S. R. M. 2000. Mapping of four major rice blast resistance genes from 'Lemont' and 'Tequing' and evaluation of their combinatorial effect for field performance. Theor. Appl. Genet. 101:1215-1225.

32. The Rice Chromosome 11 and 12 Sequencing Consortia. 2005. The sequence of rice chromosome 11 and 12, rich in disease resistance genes and recent gene duplications. BMC Biol. 3:20.

33. Wang, C. T., Tan, M. P, Xu, X., Wen, G. S., Zhang, D. P., and Lin, X. H. 2003. Localizing the bacterial blight resistance gene, Xa22(t), to a 100-kilobase bacterial artificial chromosome. Phytopathology 93:12581262.

34. Wang, L., Hu, T. Z., Yang, X. Y., Wu, W. H., and Pan, Q. H. 2004. Characterization of genetic structure of the fungus population, Magnaporthe grisea, in South China. Pages 272-275 in: Biology of Molecular Plant-Microbe Interactions, Volume 4. B. Lugtenberg, I. Tikhonovich, and N. Provorov, eds. International Society for Molecular Plant-Microbe Interactions, St. Paul, MN.

35. Wang, Z. X., Yano, M., Yamanouchi, U., Lwamoto, M., Monna, L., Hayasaka, H., Katayose, Y., and Sasaki, T. 1999. The Pib gene for rice blast resistance belongs to the nucleotide binding and leucine-rich repeat class of plant disease resistance genes. Plant J. 19:55-64.

36. Xu, X., Hayashi, N., Wang, C., Kato, H., Fujimura, T., and Kawasaki, S. 2008. Efficient authentic fine mapping of the rice blast resistance gene Pik- $h$ in the Pik cluster, using new Pik-h-differentiating isolates. Mol. Breed. 22:289-299.

37. Yang, Q., Lin, F., Feng, S., Wang, L., and Pan, Q. 2009. Recent progress on molecular mapping and cloning of blast resistance genes in rice (Oryza sativa L.). Sci. Agric. Sin. (In Chinese with English abstract) 42:16011615.

38. Yang, Z., Sun, X., Wang, S., and Zhang, Q. 2003. Genetic and physical mapping of a new gene for bacterial blight resistance in rice. Theor. Appl. Genet. 106:1467-1472.

39. Yu, Z. H., Mackill, D. J., Bonman, J. M., McCouch, S. R., Guiderdoni, E., Notteghem, J. L., and Tanksley, S. D. 1996. Molecular mapping of genes for resistance to rice blast (Pyricularia grisea Sacc.). Theor. Appl. Genet. 93:859-863.

40. Zhou, B., Qu, S., Liu, G., Dolan, M., Sakai, H., Lu, G., Bellizzi, M., and Wang, G. L. 2006. The eight amino-acid differences within three leucinerich repeats between $\mathrm{Pi} 2$ and $\mathrm{Piz}-\mathrm{t}$ resistance proteins determine the resistance specificity to Magnaporthe grisea. Mol. Plant-Microbe Interact. 19:1216-1228. 